\title{
A Comparison of the Histological Structure of the Placenta in Experimental Animals
}

\author{
Satoshi Furukawa $^{1 *}$, Yusuke Kuroda ${ }^{1}$, and Akihiko Sugiyama ${ }^{2}$ \\ ${ }^{1}$ Biological Research Laboratories, Nissan Chemical Industries, Ltd., 1470 Shiraoka-cho, Shiraoka, Saitama 349-0294, Japan \\ ${ }^{2}$ Courses of Veterinary Laboratory Medicine, School of Veterinary Medicine, Faculty of Agriculture, Tottori University, \\ 4-101 Koyama-cho Minami, Tottori 680-8553, Japan
}

\begin{abstract}
The primary function of the placenta is to act as an interface between the dam and fetus. The anatomic structure of the chorioallantoic placenta in eutherian mammals varies between different animal species. The placental types in eutherian mammals are classified from various standpoints based on the gross shape, the histological structure of the materno-fetal interface, the type of materno-fetal interdigitation, etc. Particularly, the histological structure is generally considered one of the most useful and instructive classifications for functionally describing placental type. In this system, three main types are recognized according to the cell layers comprising the interhemal area: (1) epitheliochorial type (horses, pigs and ruminants), (2) endotheliochorial type (carnivores) and (3) hemochorial type (primates, rodents and rabbits). The number of cell layers in the interhemal area is considered to modify the transfer of nutrients between maternal and fetal blood and is one of the important factors with respect to the difference in placental permeability between animal species. Therefore, in reproductive and developmental toxicity studies, careful attention should be paid to the histological structure of the interhemal area when extrapolating information concerning placental transfer characteristics to different animal species. (DOI: 10.1293/tox.2013-0060; J Toxicol Pathol 2014; 27: 11-18)
\end{abstract}

Key words: cynomolgus monkey, dog, minipig, placenta, rabbit, rat

\section{Introduction}

Reproductive and developmental toxicity studies in rats and rabbits are necessary for safety evaluation of pharmaceutical drugs, pesticides and food additives. The placenta is one of the important organs for the evaluation of risks for dams and embryos/fetuses in these toxicity studies. The placenta grows rapidly, and exhibits marked changes in morphological structure according to fetal development. Although the placenta is a temporary organ, it is the interface between the dam and developing embryos/fetuses, and a multifaceted organ that performs a number of important functions throughout gestation. These functions include anchoring the developing fetus to the uterine wall, mediating maternal immune tolerance, $\mathrm{O}_{2} / \mathrm{CO}_{2}$ exchange, providing nutrients for the fetus and removing waste products during embryonic development ${ }^{1}$. It also protects the embryo/fetus as a barrier against xenobiotics and releases a variety of steroids, hormones and cytokines. However, there is a diversity

Received: 7 November 2013, Accepted: 20 November 2013

*Corresponding author: S Furukawa (e-mail: furukawa@,

nissanchem.co.jp)

(C)2014 The Japanese Society of Toxicologic Pathology

This is an open-access article distributed under the terms of the Creative Commons Attribution Non-Commercial No Derivatives (by-ncnd) License $<$ http://creativecommons.org/licenses/by-nc-nd/3.0/> . of placental morphologies in different animal species ${ }^{2}$. The placental types in eutherian mammals are classified from various standpoints based on the gross shape, the histological structure of the materno-fetal interface, the type of materno-fetal interdigitation, etc. ${ }^{3-8}$. It is important to consider the diversity of placental morphologies when extrapolating physiological, endocrinological, immunological, or any other data from the animal to the human situation in discussion of the passage of drugs and chemicals from dams to fetuses ${ }^{5}$. In addition, the histopathological approaches to the pathogenesis of placental toxicity are considered to provide an important tool for understanding the mechanism of reproductive and developmental toxicity with particular regard to embryo lethality and delayed development ${ }^{9}$. Therefore, it is the purpose of this paper to describe the morphological placental classifications and the comparison of histological placental structure in experimental animals.

\section{Placental Classifications}

Mammalian placentas are classified into two types according to the fetal membrane including to chorion, yolk sac placenta (choriovitelline placenta) and chorioallantoic placenta. The yolk sac placenta is the vascularized trilaminar yolk sac apposed to uterine tissue, and usually plays a role as a transient placenta during the early postimplantation period before the allantoic circulation is established ${ }^{10,11}$. In 


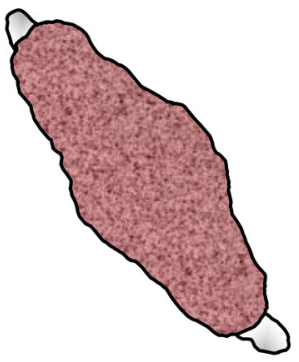

a. Diffuse

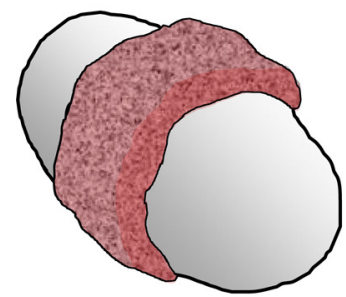

c. Zonary

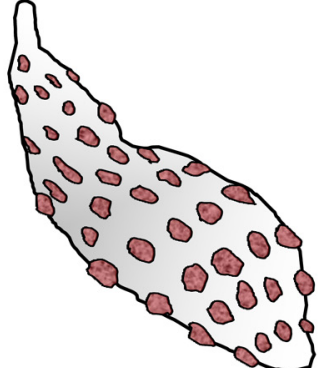

b. Multicotyledonary

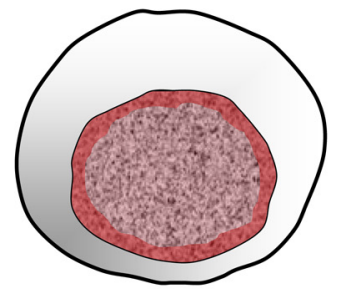

d. Discoid
Fig. 1. Classification by placental gross shape.

most mammals, the yolk sac placenta becomes vestigial after the first trimester, except in rodents and rabbits. The chorioallantoic placenta is formed from the endometrium of the dam and the trophectoderm of the embryo and is the principal placenta in mammals during middle to late-gestation. It shows a variety of shapes between different animal species based on the morphology $y^{3-8}$. Two main classifications of chorioallantoic placentas are described as below.

\section{Classification based on gross shape}

Four main types are recognized according to the gross morphology of the placenta (Fig. 1). The basis of the classification is whether materno-fetal exchange area is found over all the available surface of the chorionic sac or whether it is restricted. This classification provides a useful simplification, but within orders, there are invariably exceptions outside the usual category ${ }^{4}$.

(1) Diffuse: this type of placenta occurs over the entire surface of the uterine luminal epithelium with formation of folds/villi and is found in horses and pigs.

(2) Multicotyledonary: this type of placenta is characterized by many spot-like placental regions of the endometrium known as caruncles (from 100 to 120 caruncles in sheep and 4 caruncles in deer). Intervening areas of the chorion are smooth and relatively avascular. This type of placenta is found in ruminants.

(3) Zonary: this type of placenta shows an intimate interdigitating contact zone that forms a belt around the chorionic sac. This type of placenta is found in carnivores.

(4) Discoid/bidiscoid: this type of placenta is characterized by a single (discoid) or double disc (bidiscoid), and interaction is confined to a roughly circular area. This type of placenta is found in primates, rodents and rabbits.

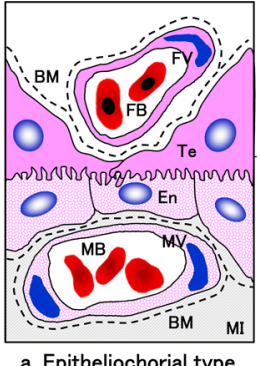

a. Epitheliochorial type

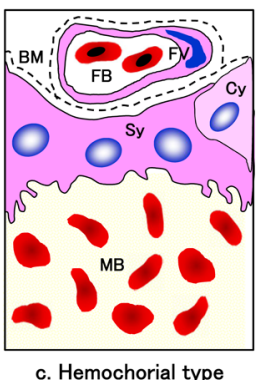

(Hemomonochorial)

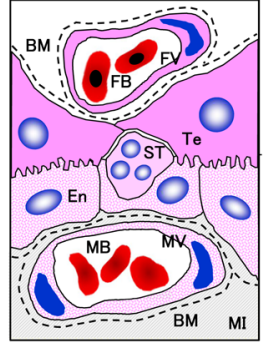

a'. Syndesmochorial type

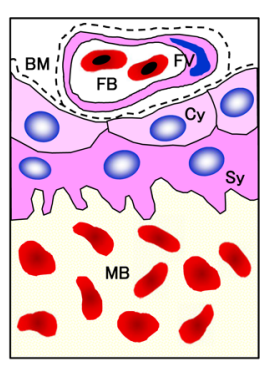

c. Hemochorial type

(Hemodichorial)
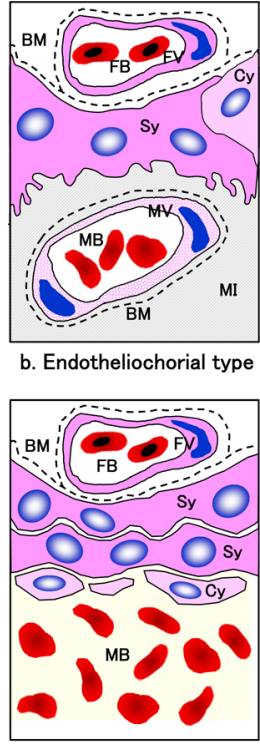

c. Hemochorial type
Fig. 2. Classification by relationship between the chorion and uterine wall. $\mathrm{BM}$, basement membrane; Te, trophectoderm; $\mathrm{Cy}$, cytotrophoblast; En, endometrium; FB, fetal blood; FV, fetal vessel; MB, maternal blood; MI, maternal interstitium; MV, maternal vessel; ST, specific trophoblast; Sy, syncytiotrophoblast.

\section{Classification based on histological structure}

Three main types are recognized according to the histologic relationship established between the chorion and uterine wall ${ }^{6,12,13}$ (Fig. 2). It is generally considered one of the most useful and instructive methods for functionally describing placental type and was proposed by Grosser ${ }^{14}$.

(1) Epitheliochorial type: this type is the most superficial placenta and lacks significant invasion of the uterine lining. Pockets of columnar trophoblasts are loosely applied to the maternal endometrial epithelium. No destruction or invasion of the maternal tissues occurs and no layers are removed. The epitheliochorial type is found in horses, pigs and ruminants. Although there is some controversy over the evolution of the placenta, it is considered that the common ancestor of living placental mammals had a moderately invasive placenta of the endotheliochorial type ${ }^{12}$. The syndesmochorial type is a placenta from which the endometrial epithelium is removed after implantation and was added to the placental classification list for a while ${ }^{14}$. However, electron microscopic examination eliminated this type from the classification because it is never found in the interhemal regions ${ }^{15}$. On the other hand, some reports have described that the syndesmochorial placenta is an unusual type of placenta for ruminants: some specific trophoblasts (the binucleate cells) fuse with a single uterine epithelial cell, giving rise to trinucleate cells or even multinucleate structures of mixed fetal and maternal origin ${ }^{16}$.

(2) Endotheliochorial type: the maternal uterine epithelium and connective tissue disappear after implantation, and 

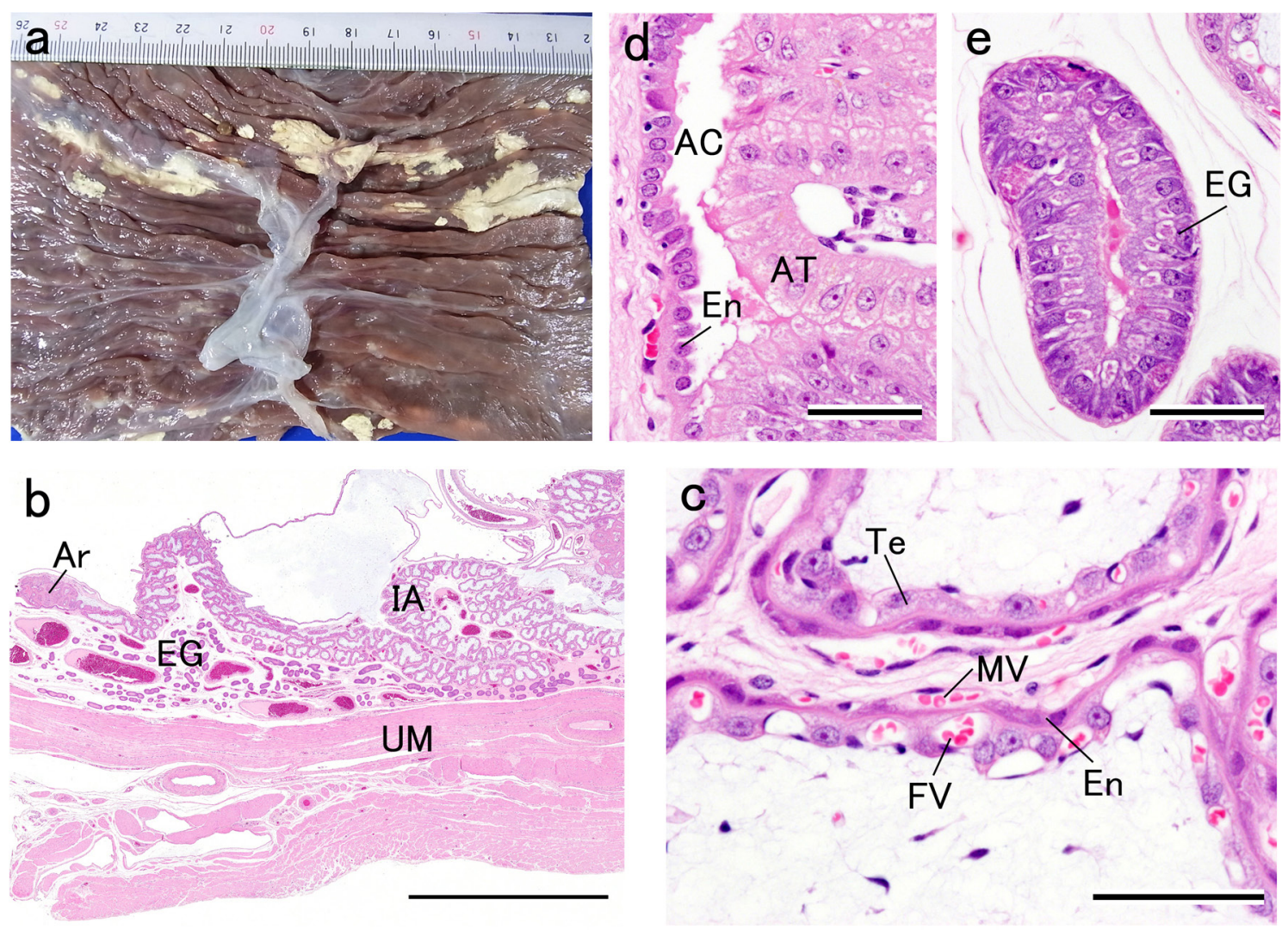

Fig. 3. Pig (minipig) placenta. Epitheliochorial type placenta. a) Gross appearance on gestation day 100. b) Histological section at low magnification. HE stain, bar $=3 \mathrm{~mm}$. c) Interhemal area. HE stain, bar $=60 \mu \mathrm{m}$. d) Areolus. HE stain, bar $=60 \mu \mathrm{m}$. e) Endometrial gland. HE stain, bar $=60 \mu \mathrm{m}$. AC, areolar cavity; Ar, areolus; AT, areolar trophectoderm; EG, endometrial gland; En, endometrium; FV, fetal vessel; IA, interhemal area; MV, maternal vessel; Te, trophectoderm; UM, uterine muscle.

the trophoblasts come into direct contact with the maternal endometrial. The endotheliochorial type occurs in orders from all four major clades of eutherian mammals (Euarchontoglires, Laurasiatheria, Xenarthra and Afrotheria), including carnivores ${ }^{17}$.

(3) Hemochorial type: this type is the most invasive placenta. All maternal tissue layers disappear through erosion, leading to direct connection between the chorion and maternal blood. There are hemomonochorial (primates), hemodichorial (rabbits), and hemotrichorial (rats and mice) placentas, with one, two and three trophoblast layers, respectively ${ }^{15,18}$

\section{Anatomical Features of Placentas in Experimen- tal Animals ${ }^{3-5,7,12,15,19-21}$}

\section{Pig (minipig)}

Pigs have an epitheliochorial and diffuse type of placenta (Fig. 3a). Histologically, the surface of the allantochorion becomes complexly folded, producing ridges that fit into corresponding grooves or crypts in the endometrium (Fig. 3b). In the interhemal area, the maternal vessels and fetal vessels are situated just below the basement membranes of the endometrium and trophectoderm without the destruction of endometrial tissue ${ }^{22,23}$ (Fig. 3c). However, the endometrium and trophectoderm are thin and deeply indented by the blood vessels as pregnancy proceeds, resulting in shorter diffusion distances across the epitheliochorial placenta $^{2}$. The interhemal distance can be as little as $2 \mu \mathrm{m}^{24}$. The depths between the chorionic folds, the so-called areolus, are lined by tall, columnar trophoblasts (areolar trophectoderm) that are actively phagocytic (Fig. 3d). Uteroferrin, an iron-containing glycoprotein, is released from the endometrial glands to the lumen, taken up by the areolar trophectoderm, and then transferred to the fetus, as an iron source $^{25}$. Many endometrial glands are observed under the endometrium (Fig. 3e).

\section{$\operatorname{Dog}$}

Dogs have an endotheliochorial and zonary type of placenta $^{26}$ (Fig. 4a). Histologically, the placenta of dogs is composed of the labyrinth zone, the junctional zone and the glandular zone (Fig. 4b). The labyrinth zone is composed of trophoblastic lamellae, in which cytotrophoblasts and syncytiotrophoblasts cover the maternal vessels (Fig. 4c). The maternal vessels are surrounded by a noncellular layer, 

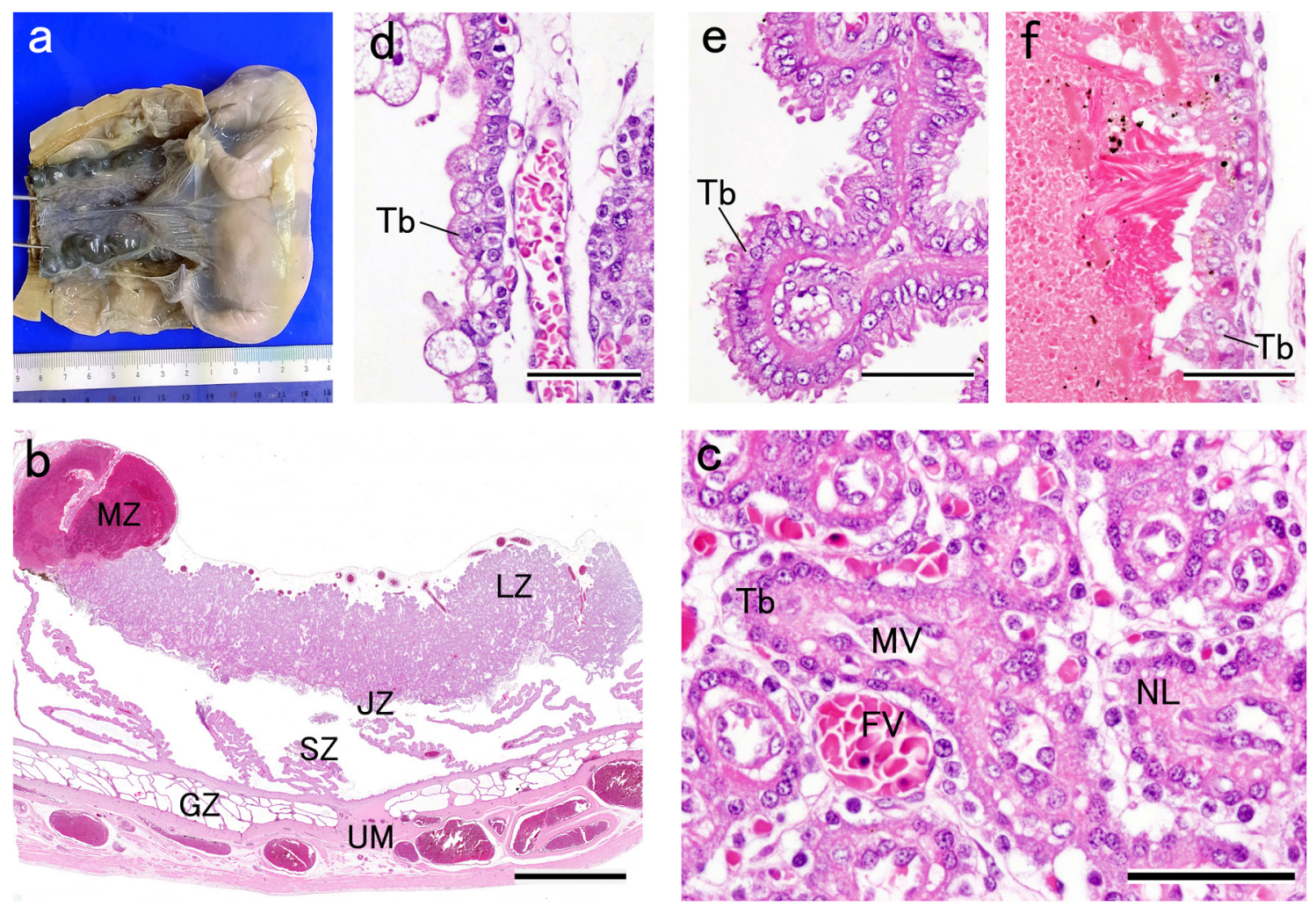

Fig. 4. Dog placenta. Endotheliochorial type placenta. a) Gross appearance on gestation day 35. b) Histological section at low magnification. HE stain, bar=3 mm. c) Labyrinth zone. HE stain, bar=60 $\mu \mathrm{m}$. d) Junctional zone. HE stain, bar $=60 \mu \mathrm{m}$. e) Sponge zone. HE stain, bar $=60 \mu \mathrm{m}$. f) Marginal hemophagous zone. HE stain, bar $=60 \mu \mathrm{m}$. FV, fetal vessel; GZ, glandular zone; LZ, labyrinth zone; JZ, junctional zone; MV, maternal vessel; MZ, marginal hemophagous zone; NL, noncellular layer; SZ, sponge zone; Tb, trophoblast; $\mathrm{UM}$, uterine muscle.

which is positive for periodic acid-Schiff (PAS) stain and Alcian blue stain. The fetal vessels deeply indent the trophoblasts. The junctional zone is an area of transition between the labyrinth zone and gland zone (Fig. 4d). The trophoblasts, which show tall columnar cells in monolayers with microvilli on the free surface, invade into the endometrial gland cavity. Particularly, the deep part of the junctional zone is called the sponge zone (Fig. 4e). The glandular zone is composed of the remnants of endometrial glands. These glands become distended by retained secreted function as the result of obstruction of their mouths by penetrating trophoblasts (Fig. 4b). Marginal hemophagous zones filled with maternal blood develop at both edges of the placenta or in the middle of the placenta ${ }^{22}$ (Fig. 4f). They are lined by high columnar trophectoderm showing active phagocytosis and digestion of erythrocytes, and are considered to have a relationship with placental iron transport ${ }^{27}$.

\section{Rat and mouse}

Rats and mice have a hemotrichorial and discoid type of placenta, ${ }^{98}$ (Fig. 5a). Histologically, the placenta of rats and mice is composed of the labyrinth zone, the basal zone, the decidua and the metrial glands ${ }^{29-32}$ (Fig. 5b). In the labyrinth zone, there are three layers of trophoblasts, separating the maternal blood spaces from the fetal blood vessels $^{2,18}$ (Fig. 5c). The outer trophectoderm, which comes into direct contact with the maternal blood, is referred to as cytotrophoblasts with a microvillous surface. Under this trophectoderm, there are two layers of syncytiotrophoblasts. The basal zone is comprised of three types of differentiated cells: (1) spongiotrophoblasts, (2) trophoblastic giant cells and (3) glycogen cells (Fig. 5d). The spongiotrophoblasts are present immediately above the trophoblastic giant cell layer located at the materno-fetal placental interface. The glycogen cells form multiple small cell masses and develop into glycogen cell islands in midgestation, and then most of them disappear before parturition. The decidua is comprised of the mesometrial decidual cells ultimately, and plays essential roles in the development of the vascularized decidual-placental interface. The metrial gland is located in the mesometrial triangle of the pregnant uterus from early gestation and is fully developed in midgestation, leading to regression before parturition ${ }^{30,33}$. It is composed of decidualized endometrial stromal cells, uterine natural killer cells, spinal-shaped arteries, trophoblasts originating from glycogen cells, and fibroblasts ${ }^{34,35}$ (Fig. 5e). The yolk sac is composed of epithelial cells and mesodermal cells (Fig. 5f) and is divided into visceral and parietal parts. Because the parietal yolk sac ruptures in midgestation, the inside of the visceral yolk sac becomes exposed to the intrauterine cavity 

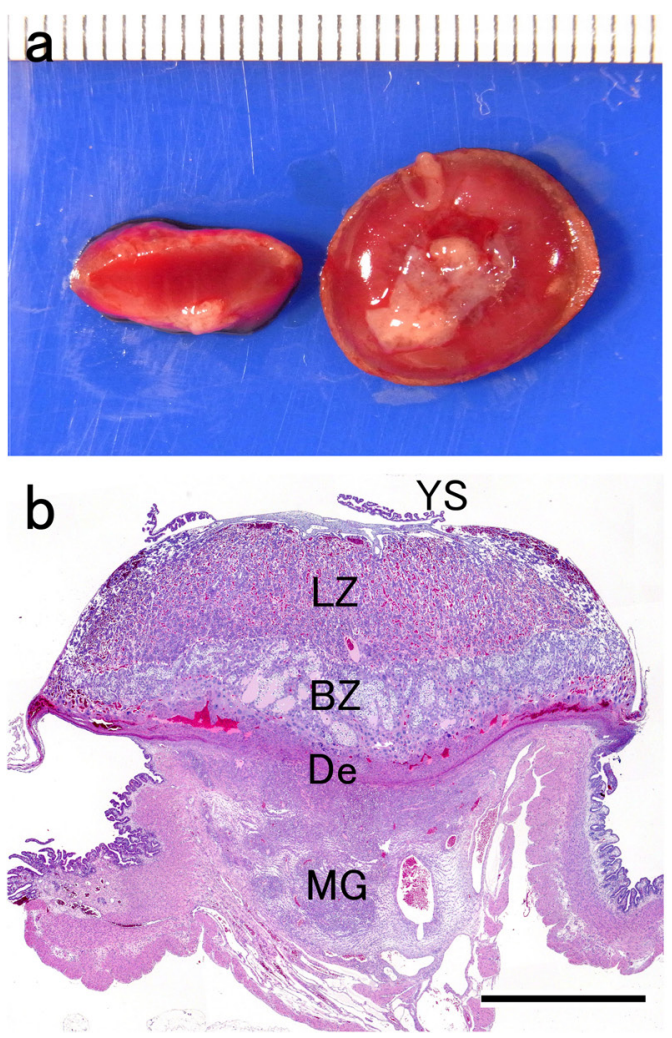
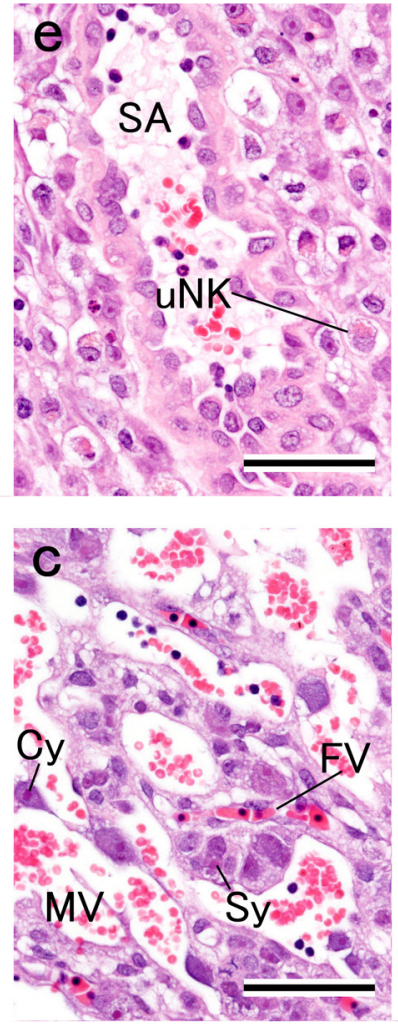
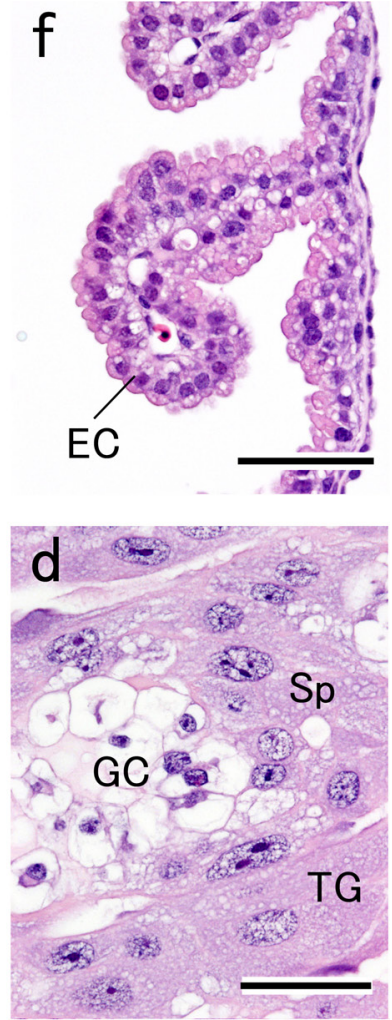

Fig. 5. Rat placenta. Hemotrichorial type placenta. a) Gross appearance on gestation day 15. b) Histological section at low magnification. HE stain, bar $=2 \mathrm{~mm}$. c) Labyrinth zone. HE stain, bar $=60 \mu \mathrm{m}$. d) Basal zone. HE stain, bar=60 $\mu \mathrm{m}$. e) Metrial gland. HE stain, bar $=60 \mu \mathrm{m}$. f) Yolk sac. HE stain, bar $=60 \mu \mathrm{m}$. BZ, basal zone; Cy, cytotrophoblast; De, decidua; EC, epithelial cell; FV, fetal vessel; GC, glycogen cell; LZ, labyrinth zone; MG, metrial glands; MV, maternal vessel; SA, spiral artery; Sp, spongiotrophoblast; Sy, syncytiotrophoblast; TG, trophoblastic giant cells; uNK, uterine natural killer; YS, yolk sac.

and is called a reversed yolk sac placenta, which functions throughout pregnancy.

\section{Rabbit}

Rabbits have a hemodichorial and bidiscoid type of placenta $^{22,28,36}$ (Fig. 6a). Histologically, the placenta of rabbits is composed of the labyrinth zone, the junctional zone, the decidua'zone of necrosis, the decidua zone of separation, and the mesometrium ${ }^{37,38}$ (Fig. 6b). In the labyrinth zone, there are two layers of trophoblasts, an outer and inner layer separating the maternal blood spaces from the fetal blood vessels ${ }^{2,22,39}$ (Fig. 6c). The outer trophectoderm, which comes into direct contact with the maternal blood, is comprised of the syncytiotrophoblasts, which are joined to the underlying cytotrophoblast layer by adhesion junctions. The inner trophectoderm is one layer of cytotrophoblasts overlying fetal blood vessels. The junctional zone is composed of glycogen cells containing PAS-positive substances (Fig. 6d). These cells are transiently detected in midgestation, and disappear before parturition. The decidua originates from stromal cells of the mesometrial endometrium and is divided into the zone of necrosis and the zone of separation in midgestation. The zone of necrosis develops with dilated blood vessels as pregnancy advances. This zone is detected under the junctional zone and is composed of necrotic tissue. The zone of separation becomes thinner without necrosis as pregnancy advances (Fig. 6e). The structure and functions of the yolk sac placenta are the same as those of rats and mice (Fig. 6f).

\section{Cynomolgus monkey}

Cynomolgus monkeys have a hemomonochorial and bidiscoid type of placenta ${ }^{28}$ (Fig. 7a). Histologically, the placenta of cynomolgus monkeys is composed of the placental villi, the chorionic plate, the basal plate and the decidua $a^{31,40}$ (Fig. 7b). The placental villi protrude into the intervillous space and are bathed directly in maternal blood. The anchoring villi are peripheral ones that are connected to the basal zone. The placental villous surface is composed of an outer continuous layer of syncytiotrophoblasts in contact with maternal blood and an inner discontinuous layer of cytotrophoblasts ${ }^{2,41}$ (Fig. 7c). The stroma of the placental villi is composed of fetal vessels and mesenchyme. The chorionic plate is populated with mesenchymal cells within a fibrous connective tissue, and represents the cover of the intervillous space. Tree-like arranged placental villi arise from the chorionic plate (Fig. 7d). The basal plate is the bottom of the intervillous space and the junction of the endometrium 

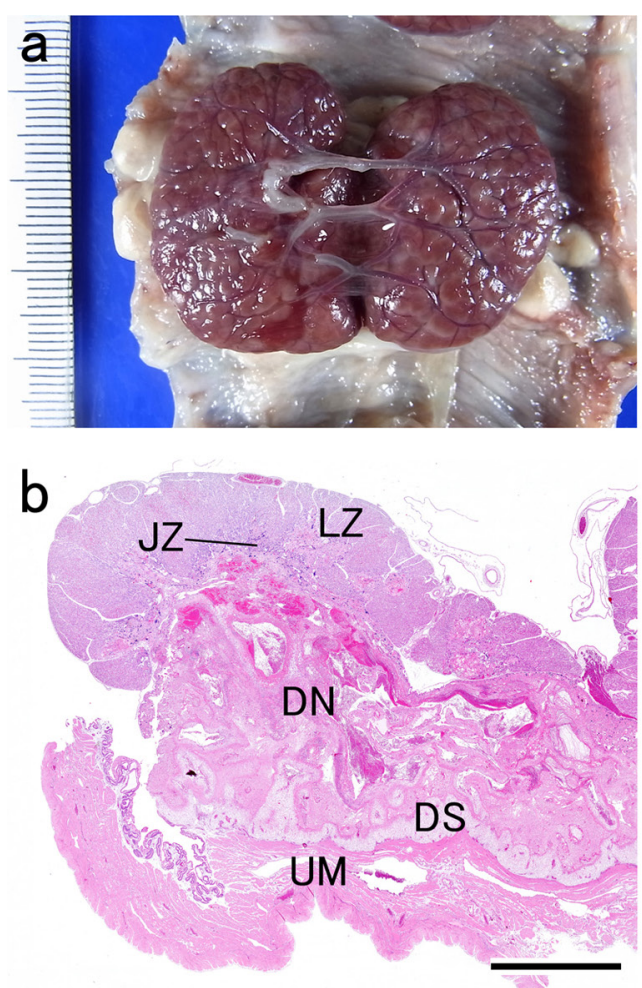
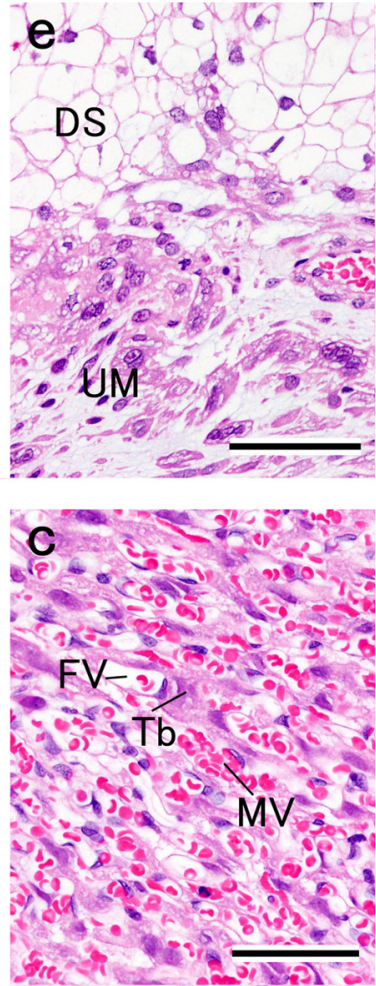
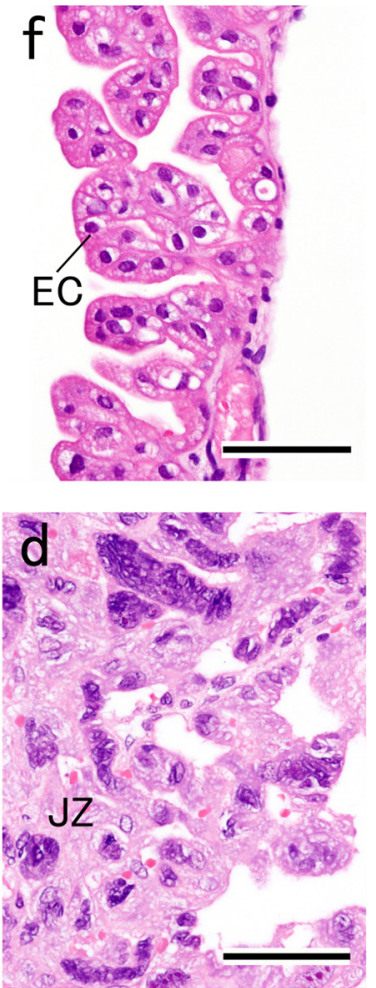

Fig. 6. Rabbit placenta. Hemodichorial type placenta. a) Gross appearance on gestation day 28. b) Histological section at low magnification. HE stain, bar $=3 \mathrm{~mm}$. c) Labyrinth zone. HE stain, bar $=60 \mu \mathrm{m}$. d) Junctional zone. HE stain, bar $=60 \mu \mathrm{m}$. e) Decidua. HE stain, bar $=60 \mu \mathrm{m}$. f) Yolk sac. HE stain, bar=60 $\mu \mathrm{m}$. DN, decidua, zone of necrosis; DS, decidua, zone of separation; EC, epithelial cell; FV, fetal vessel; $\mathrm{JZ}$, junctional zone; LZ, labyrinth zone; MV, maternal vessel; Tb, trophoblast; UM, uterine muscle.
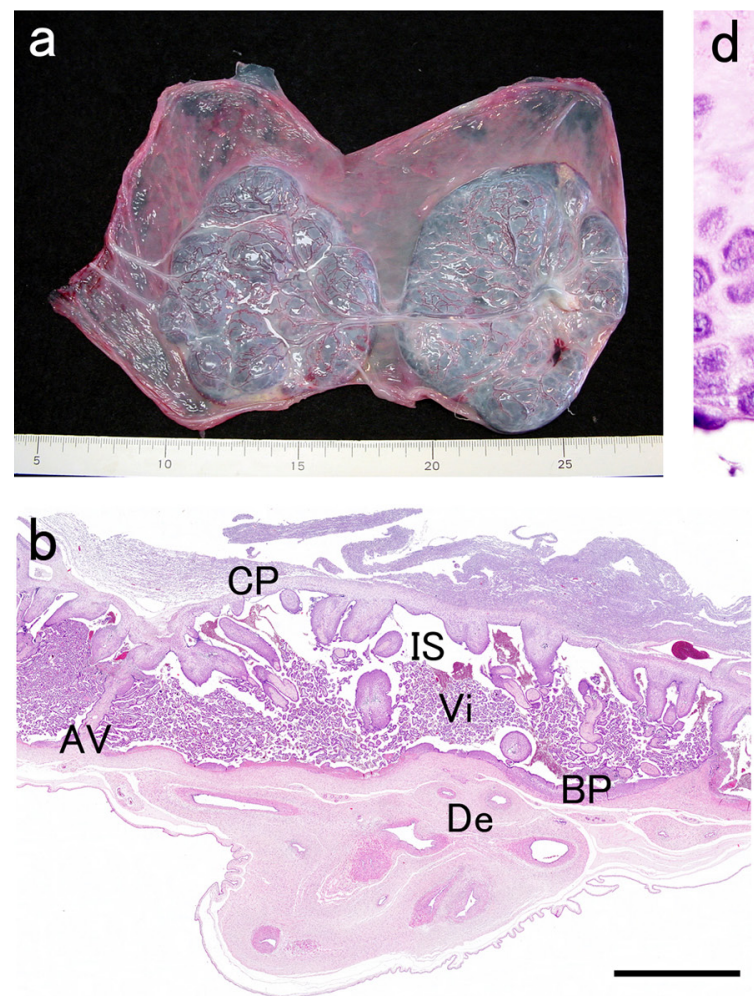
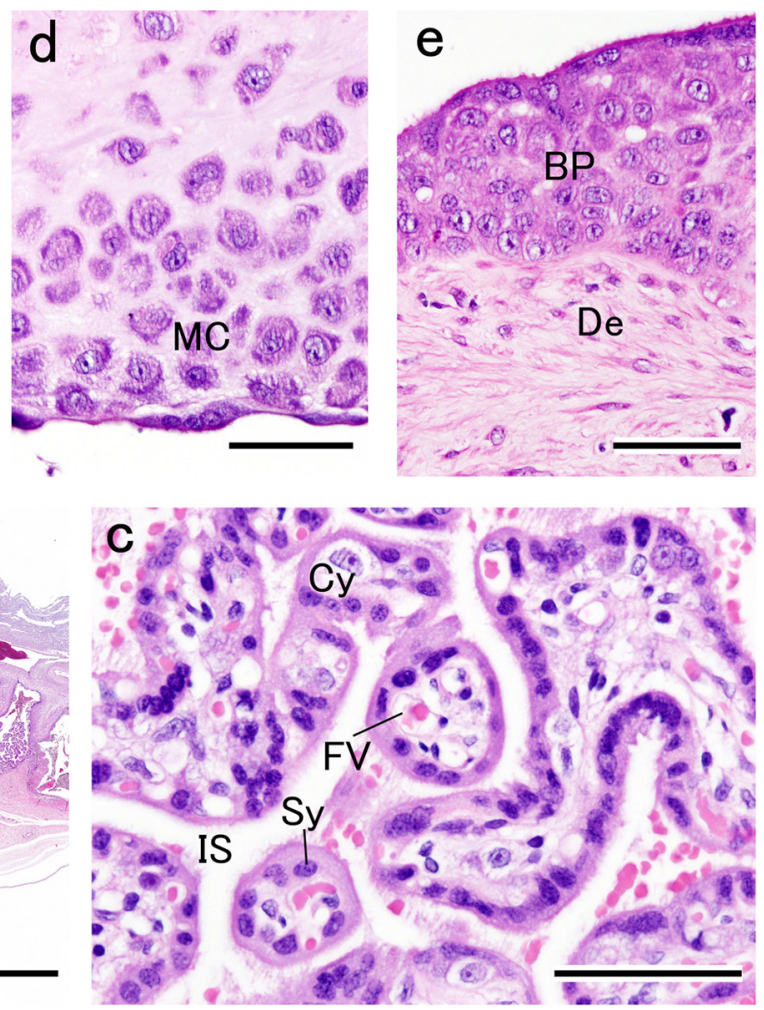

Fig. 7. Cynomolgus monkey placenta. Hemomonochorial type placenta. a) Gross appearance on gestation day 111. b) Histological section at low magnification. HE stain, bar $=3 \mathrm{~mm}$. c) Villus. HE stain, $b a r=60 \mu \mathrm{m}$. d) Chorionic plate. HE stain, bar $=60 \mu \mathrm{m}$. e) Basal plate and decidua. HE stain, bar $=60 \mu \mathrm{m}$. AV, anchoring villus; BP, basal plate; CP, chorionic plate; Cy, cytotrophoblast; De, decidua; FV, fetal vessel; IS, intervillous space; MC, mesenchymal cell; Sy, syncytiotrophoblast; Vi, villus. 
with fetal tissues (Fig. 7e). The basal plate is composed of extravillous cytotrophoblasts, endometrial stromal cells, decidual cells, etc. The placenta of cynomolgus monkeys is very similar to the human placenta ${ }^{2}$.

\section{Placental Permeability Between Different Ani- mal Species}

The fully formed placenta plays a major role in maintenance of nutrition for the fetus and in the secretory and essential regulatory functions for maintenance of pregnancy during the fetal period. As described in this brief review of the anatomical placentas in some experimental animals, the composition of intervening cells in the interhemal areas is different between animal species. Molecules cross the placenta either by diffusion or some form of active or facilitated transport. In the case of diffusion, the ability for molecules to cross the placenta in either direction is strongly influenced by the interhemal distance or the thickness of the cellular barrier between maternal and fetal blood. A small interhemal distance generally will increase the rate at which molecules can transfer between maternal and fetal blood, either by diffusion or active transport. Thus, the number of cell layers separating the maternal from the fetal blood is considered to be important in modifying the transfer of nutrients and forming the materno-fetal barrier ${ }^{42-44}$. Actually, fatty acids and keto acids are readily transferred from dams to fetuses in the hemochorial placenta of rodents, rabbits and primates, whereas their uptake by ruminants, pigs and horses is very low ${ }^{42}$. In addition, the pig is not suitable as an informative model for the study of antibody therapeutics in embryo-fetal toxicity studies, since the pig placenta is impermeable to the passage of macromolecules such as immunoglobulins ${ }^{45}$. Also, it is known that there are at least three different mechanisms for iron transport, according to the structure of the maternal-fetal interface ${ }^{46}$ (hemochorial, penetration; endotheliochorial, phagocytosis; epitheliochorial, secretion). On the other hand, it is known that there are regions of the pig placenta where the six cell layers of the maternofetal barrier become sufficiently thinned to equal the minimal interhemal distance of the three cell layers in a human placenta, although the mean interhemal distance in the pig placenta is greater than the mean in the human placenta 24 . There does not appear to be any difficulty in allowing for the passage of substances based simply on the number of layers separating the different blood supplies, even though there may be differences in transit times ${ }^{8}$. In addition, the disadvantage of the greater difficulty in passage of materials between organisms is partially overcome by a variety of mechanisms ${ }^{20}$. Therefore, it has been reported that the interspecies differences in the type of placenta do not play a dominant role in the placental transfer of most drugs, which is determined largely by placental blood flow ${ }^{43}$. At any rate, it should be considered that the histological structure separating the maternal blood from the fetal blood modifies the transfer of nutrients, and that the placental structure is one of the important factors for its permeability between differ- ent animal species

In conclusion, the chorioallantoic placenta shows morphological diversity in experimental animals. In reproductive and developmental toxicity studies, careful attention should be paid to the histological structure of the interhemal area when extrapolating information concerning placental transfer characteristics to different animal species.

Acknowledgements: The authors would like to thank Ms. Mayumi Kano (Nihon Bioresearch Inc.) and Mr. Kazuhiko Nakayama (Nippon Institute for Biological Science) for the minipig placenta, Dr. Toru Hoshiya (BoZo Research Center Inc.) for the rabbit placentas, Dr. Tsuyoshi Yoshikawa and Dr. Akihiro Arima (Shin Nippon Biomedical Laboratories, Ltd.) for the cynomolgus monkey placenta, and Mr. Kiyoshi Kobayashi, Ms. Kaori Maejima, Ms. Hiromi Asako, Mr. Atsushi Funakoshi, Mr. Yoshinori Tanaka, Ms. Chika Yanagida, Ms. Mayumi Shimada, and Ms. Chieko Furubayashi (Nissan Chemical Industries, Ltd.) for their excellent technical assistance.

\section{References}

1. Bauer MK, Harding JE, Bassett NS, Breier BH, Oliver MH, Gallaher BH, Evans PC, Woodall SM, and Gluckman PD. Fetal growth and placental function. Mol Cell Endocrinol. 140: 115-120. 1998. [Medline] [CrossRef]

2. Enders AC, and Blankenship TN. Comparative placental structure. Adv Drug Deliv Rev. 38: 3-15. 1999. [Medline] [CrossRef]

3. Ramsey EM. The placenta. Human and Animal. Praeger, New York. 1982.

4. Wooding P, and Burton G. Comparative Placentation. Structures, Functions and Evolution. Springer, Berlin. 2008.

5. Burton GJ, Kaufmann P, and Huppertz B. Anatomy and genesis of the Placenta. In: Knobil and Nell's Physiology of Reproduction. 3rd ed. JD Neill (ed). Academic Press, Amsterdam. 189-243. 2006.

6. Leiser R, and Kaufmann P. Placental structure: in a comparative aspect. Exp Clin Endocrinol. 102: 122-134. 1994. [Medline]

7. Telugu BP, and Green JA. Comparative placentation. In: Comparative Reproductive Biology, 1st.ed. H Schatten, and GE Constantinescu (eds). Blackwell Publishing, Iowa. 271-319. 2007.

8. Slikker W, and Miller RK. Placental metabolism and transfer role in developmental toxicology. In: Developmental Toxicology, 2nd ed. CA Kimmel, and J Buelke-Sam (eds). Raven Press, New York. 245-283. 1994.

9. Furukawa S, Hayashi S, Usuda K, Abe M, Hagio S, and Ogawa I. Toxicological pathology in the rat placenta. J Toxicol Pathol. 24: 95-111. 2011. [Medline] [CrossRef]

10. Cross JC, Werb Z, and Fisher SJ. Implantation and the placenta: key pieces of the development puzzle. Science. 266: 1508-1518. 1994. [Medline] [CrossRef]

11. Jollie WP. Development, morphology, and function of the yolk-sac placenta of laboratory rodents. Teratology. 41: 361-381.1990.

12. Carter AM, and Martin RD. Comparative anatomy and 
placental evolution. In: Placental Bed Disorders, 1st ed. R Pijnenborg, I Brosens, and R Romero (eds). Cambridge University Press, Cambridge. 109-126. 2010.

13. Enders AC, and Carter AM. Comparative placentation: some interesting modifications for histotrophic nutrition - a review. Placenta. 27: 11-16. 2006. [CrossRef]

14. Grosser O. Vergleichende Anatomie Und Entwicklungsgeschichte Der Eihäute Und Der Placenta, Mit Besonderer Berücksichtigung Des Menschen. HardPress, Miami. 1909.

15. Steven DH. Anatomy of the placental barrier. In: Comparative Placentation; Essays in Structure and Function. 1st. ed. Steven DH (ed). Academic Press, London. 25-57. 1975.

16. Cornelis G, Heidmann O, Degrelle SA, Vernochet C, Lavialle $\mathrm{C}$, Letzelter C, Bernard-Stoecklin S, Hassanin A, Mulot B, Guillomot M, Hue I, Heidmann T, and Dupressoir A. Captured retroviral envelope syncytin gene associated with the unique placental structure of higher ruminants. PNAS. 110: E828-E837. 2013. [Medline] [CrossRef]

17. Enders AC, and Carter AM. The evolving placenta: convergent evolution of variations in the endotheliochorial relationship. Placenta. 33: 319-326. 2012. [Medline] [CrossRef]

18. Takata K, Fujikura K, and Shin B. Ultrastructure of the rodent placental labyrinth: a site of barrier and transport. J Reprod Dev. 43: 13-24. 1997. [CrossRef]

19. Enders AC, Blankenship TN, Lantz KC, and Enders SS. Morphological variation in the interhemal areas of chorioallantoic placenta - a review -. Trophoblast Res. 12: 1-19. 1998.

20. Enders AC, and Carter AM. What can comparative studies of placental structure tell us? -a review. Placenta. 25 (Suppl A): S3-S9. 2004. [Medline] [CrossRef]

21. Björkman N. An Atlas of Placental Fine Structure. Bailliere Tindall \& Cassell, London. 1970.

22. Perry JS. The mammalian fetal membranes. J Reprod Fertil. 62: 321-335. 1981. [Medline] [CrossRef]

23. Leiser R, Pfarrer C, Abd-Elnaeim M, and Dantzer V. Fetomaternal anchorage in epitheliochorial and endotheliochorial placental types studied by histology and microvascular corrosion casts. Trophoblast Res. 12: 21-39. 1998.

24. Power ML, and Schulikn J. The Evolution of the Human Placenta. The Johns Hopkins University, Baltimore. 2012.

25. Raub TJ, Bazer FW, and Roberts RM. Localization of the iron transport glycoprotein, uteroferrin, in the porcine endometrium and placenta by using immunocolloidal gold. Anat Embryol (Berl). 171: 253-258. 1985. [Medline] [CrossRef]

26. Miglino MA, Ambrósio CE, dos Santos Martins D, Wenceslau CV, Pfarrer C, and Leiser R. The carnivore pregnancy: the development of the embryo and fetal membranes. Theriogenology. 66: 1699-1702. 2006. [Medline]

27. Baker E, and Morgan EH. Placental iron transfer in the cat. J Physiol. 232: 485-501. 1973. [Medline]

28. Carter AM. Animal models of human placentation - a review. Placenta. 28 (Suppl A): S41-S47. 2007. [Medline] [CrossRef]

29. Soares MJ, Chakraborty D, Karim Rumi MA, Konno T, and Renaud SJ. Rat placentation: an experimental model for investigating the hemochorial maternal-fetal interface. Placenta. 33: 233-243. 2012. [Medline] [CrossRef]

30. Furukawa S, Hayashi S, Abe M, Hagio S, Irie K, Kuroda
Y, Ogawa I, and Sugiyama A. Background data on developmental parameters during the gestation period in rats. $\mathrm{J}$ Toxicol Pathol. 26: 83-88. 2013. [Medline] [CrossRef]

31. Cline JM, Dixon D, Ernerudh J, Faas MM, Göhner C, Häger JD, Markert UR, Pfarrer C, Svensson-Arvelund J, and Buse E. The placenta in toxicology. Part III: pathologic assessment of the placenta. Toxicol Pathol. 2013; (in press). [Medline] [CrossRef]

32. Davies J, and Glasser SR. Histological and fine structural observations on the placenta of the rat. Acta Anat (Basel). 69: 542-608. 1968. [Medline] [CrossRef]

33. Peel S. Granulated metrial gland cells. Adv Anat Embryol Cell Biol. 115: 1-112. 1989. [Medline] [CrossRef]

34. Carter AM, Enders AC, Jones CJ, Mess A, Pfarrer C, Pijnenborg R, and Soma H. Comparative placentation and animal models: patterns of trophoblast invasion - a workshop report. Placenta. 27 (Suppl A): S30-S33. 2006. [Medline] [CrossRef]

35. Vercruysse L, Caluwaerts S, Luyten C, and Pijnenborg R. Interstitial trophoblast invasion in the decidua and mesometrial triangle during the last third of pregnancy in the rat. Placenta. 27: 22-33. 2006. [Medline] [CrossRef]

36. Hafez ES, and Tsutsumi Y. Changes in endometrial vascularity during implantation and pregnancy in the rabbit. Am J Anat. 118: 249-282. 1966. [Medline] [CrossRef]

37. Mossman HW. The rabbit placenta and the problem of placental transmission. Am J Anat. 37: 433-497. 1926. [CrossRef]

38. Kotera K. Histological observation of the chronological changes in the constituent zones of the rabbit placenta. Jpn J Anim Reprod. 32: 69-77. 1986. [CrossRef]

39. Enders AC. A comparative study of the fine structure of the trophoblast in several hemochorial placentas. Am J Anat. 116: 29-67. 1965. [Medline] [CrossRef]

40. de Rijk EPCT, and Esch EV. The macaque placenta- a mini-review. Tox Pathol. 36 (Suppl): 108S-118S. 2008. [CrossRef]

41. Buse E, Häeger JD, Svensson-Arvelund J, Markert UR, Faas MM, Ernerudh J, Dixon D, Cline JM, and Pfarrer C. The placenta in toxicology. Part I: animal models in toxicology: placental morphology and tolerance molecules in the cynomolgus monkey (Macacafascicularis). Toxicol Pathol. 2013; (in press). [Medline] [CrossRef]

42. Père MC. Materno-foetal exchanges and utilisation of nutrients by the foetus: comparison between species. Reprod Nutr Dev. 43: 1-15. 2003. [Medline] [CrossRef]

43. Mihaly GW, and Morgan DJ. Placental drug transfer: effects of gestational age and species. Pharmacol Ther. 23: 253-266. 1983. [Medline] [CrossRef]

44. Miller RK, Koszalka TR, and Brent RL. The transport of molecules across placental membranes. In: The Cell Surface in Animal Embryogenesis and Development. 1st ed. G Posete, and GL Nicolson (eds). North-Holland Publishing Company, Amsterdam. 145-222. 1976.

45. Bode G, Clausing P, Gervais F, Loegsted J, Luft J, Nogues $\mathrm{V}$, and Sims J. The utility of the minipig as an animal model in regulatory toxicology. J Pharmacol Toxicol Methods. 62: 196-220. 2010. [Medline] [CrossRef]

46. Schröder HJ. Comparative aspects of placental exchange functions. Eur J Obstet Gynecol Reprod Biol. 63: 81-90. 1995. [Medline] [CrossRef] 